\title{
Atos fundantes da Faculdade de Medicina do Triângulo Mineiro: entre o ideal e o concretizado (1953-1960)
}

\author{
Foundation acts of the medical faculty of the Triângulo Mineiro: \\ between the ideal and the concretized (1953-1960) \\ Actos fundantes de la facultad de medicina del Triángulo Mineiro: \\ entre lo ideal y lo concretado (1953-1960)
}

SONIA MARIA GOMES LOPES ${ }^{1}$; SAUlOÉBER TARSIO DE SOUZA²

\section{Resumo}

O texto apresenta a trajetória inicial da Faculdade de Medicina do Triângulo Mineiro em Uberaba-MG, no período entre 1953 e 1960. Foi o primeiro curso de Medicina da região, contribuindo para o desenvolvimento do seu campo médico. Até o advento de sua criação, os aspirantes a esse curso só podiam frequentá-lo nas capitais, especialmente no Rio de Janeiro. O grupo que participou do processo de implantação dessa instituição era composto por médicos da cidade, advogado e deputado federal e a maior parte do seu corpo docente foi indicada por mestres das Escolas de Medicina das capitais do sudeste. Os egressos do curso eram originários de cidades do interior e da capital mineiras, além de São Paulo e Goiás. O seu processo de federalização decorreu da ação política de seus administradores buscando viabilizar a manutenção da instituição que não conseguia ser viabilizada apenas com as anuidades dos alunos e subsídios governamentais.

Palavras-chave: História das Instituições Escolares. Ensino Superior. Faculdade de Medicina do Triângulo Mineiro.

\footnotetext{
1 Mestre em Educação pelo Programa de Pós-Graduação em Educação da Universidade Federal de Uberlândia (UFU). Pedagoga em exercício na Universidade Federal do Triângulo Mineiro. E-mail: soniagomeslopes@hotmail.com

${ }^{2}$ Doutor em Educação pela Universidade Estadual de Campinas, com estágio de pós-doutorado concluído na Universidade Federal de São Paulo. Professor Associado III na Universidade Federal de Uberlândia. E-mail: sauloeber@gmail.com
} 


\begin{abstract}
Abstratc
The text presents the initial trajectory of the Medical School of the Triangulo Mineiro in Uberaba-MG, between 1953 and 1960. It was the first medical course in the region, contributing to the development of its medical field. Until the advent of its creation, the aspirants to this course could only attend it in the capitals, especially in Rio de Janeiro. The group that participated in the implantation process of this institution was composed of city doctors, lawyer and federal deputy and most of its faculty was indicated by masters of the Schools of Medicine of the capitals of the Southeast. The graduates of the course originated from cities in the interior and the capital of Minas Gerais, as well as São Paulo and Goiás. It's federalization process was the result of the political action of their administrators seeking to make possible the maintenance of the institution that could not be made possible only with the annuities of students and government subsidies.
\end{abstract}

Keywords: History of School Institutions. Higher Education. Medical School of Triângulo Mineiro.

\title{
Resumen
}

El texto presenta la trayectoria inicial de la Facultad de Medicina del Triángulo Minero en Uberaba-MG, en el período entre 1953 y 1960. Fue el primer curso de Medicina de la región, contribuyendo para el desarrollo de su campo médico. Hasta el advenimiento de su creación, los aspirantes a ese curso sólo podían frecuentarlo en las capitales, especialmente en Río de Janeiro. El grupo que participó en el proceso de implantación de esa institución estaba compuesto por médicos de la ciudad, abogado y diputado federal y la mayor parte de su cuerpo docente fue indicada por maestros de las Escuelas de Medicina de las capitales del sudeste. Los egresados del curso eran originarios de ciudades del interior y de la capital minera, además de São Paulo y Goiás. Su proceso de federalización se debió a la acción política de sus administradores buscando viabilizar el mantenimiento de la institución que no conseguía ser viabilizada apenas con las anualidades de los ciudadanos, alumnos y subsidios gubernamentales.

Palabras-clave: Historia de las Instituciones Escolares; Enseñanza Superior, Facultad de Medicina del Triângulo Mineiro. 


\section{Introdução}

O texto tem como proposta apresentar algumas reflexões sobre o processo de criação, implantação e federalização da Faculdade de Medicina do Triângulo Mineiro - FMTM, na cidade de Uberaba-MG, no período entre 1953 a 1960, quando funcionou como instituição particular de ensino $^{3}$. A FMTM foi a primeira instituição a ofertar o curso de Medicina na região do Triângulo Mineiro, sendo o quarto no Estado de Minas Gerais e o $22^{\circ}$ criado no Brasil.

A criação dessa instituição em uma cidade do interior mineiro teve papel fundamental do grupo de médicos envolvidos também na política local. Pode-se afirmar que o embrião da FMTM surgiu com a criação da Sociedade de Medicina e Cirurgia de Uberaba que era uma entidade de classe, mas ao mesmo tempo, de socialização dos saberes médicos produzidos por profissionais e instituições científicas da área. Nos Congressos Médicos promovidos pela SMCU surgiram as primeiras inspirações no sentido de se criar uma faculdade de medicina na cidade. Muito embora, no processo de criação da FMTM todas as evidências indiquem que foi um processo basicamente desenvolvido na esfera política, entendemos que atendeu também aos anseios mais amplos da sociedade local, interessada em melhores condições de atendimento a saúde no município.

Em relação à metodologia do trabalho, adotou-se a pesquisa qualitativa inserida na perspectiva da história das instituições escolares, subárea temática da ciência histórico educativa. Nas investigações sobre a FMTM foram utilizados documentos institucionais, obras de memorialistas da cidade e jornais, portanto, fontes de natureza documental, tais como atas de fundação da entidade mantenedora, atas da congregação, matriz curricular, atas de colação de grau, primeiro regimento geral, Revista do Centro Acadêmico Gaspar Vianna, matérias dos jornais Lavoura e Comércio, O Triângulo e Correio Católico. Além disso, consultamos também os escritos de memorialistas da região como Edelweiss Teixeira, Guido Bilharinho José Soares Bilharinho, entre outros.

O artigo está organizado em três seções além da introdução e considerações finais, de forma que na primeira, fazemos breve apresentação do cenário de criação da FMTM, na segunda abordamos os primórdios dessa instituição no município de Uberaba-MG e na terceira o processo de federalização da FMTM.

\section{Uberaba do "Sertão da Farinha Podre": do povoamento a cidade-polo}

O povoamento da região que hoje corresponde ao Triângulo Mineiro teve início com a expedição de Bartolomeu Bueno da Silva, conhecido como velho Anhanguera, atravessando em 1682, os sertões rumo às minas de ouro em Goiás assim surgiu Uberaba como um entreposto que ligava São Paulo aos minérios preciosos e que serviu de parada para as expedições que adentravam ao interior do território brasileiro. Outro fator de povoamento do Triângulo foi a queda na produção do outro em Minas Gerais, que forçou a migração de parte da sua população para outras regiões.

\footnotetext{
${ }^{3} \mathrm{O}$ artigo apresenta parte dos resultados da dissertação de mestrado de Sônia Maria Gomes Lopes intitulada "A Criação da Faculdade de Medicina do Triângulo Mineiro: primeiros anos como Instituição Privada (1953 1960)", defendida no Programa de Pós-graduação em Educação da Universidade Federal de Uberlândia sob a orientação do professor Sauloéber Tarsio de Souza.
} 
O fim da exploração dos minérios em Desemboque ${ }^{4}$, foi decisivo para a colonização definitiva da área localizada entre os rios da Velha e Grande, que se tornou conhecida a partir daí como "Sertão da Farinha Podre". Entre aqueles que se deslocaram da região dos garimpos exauridos para o "Sertão da Farinha Podre" estava o sargento-mor Antônio Eustáquio da Silva e Oliveira, que chegou ao Rio Uberaba e se fixou na margem esquerda do Córrego das Lages, onde construiu a Chácara da Boa Vista, indicada como o núcleo inicial do novo arraial que atraiu comerciantes, criadores de gado, boiadeiros, mascates, ferreiros e outros, tendo inicio a história do povoamento de Uberaba, tendo como marco o ano de 1816. De arraial foi elevada à Vila de Santo Antônio de Uberaba em 1836, e à categoria de cidade pela Lei Provincial n. 759, de 02 de maio de 1856, consolidando-se como um importante centro comercial abastecedor do Triângulo Mineiro, Goiás e Mato Grosso. Outro fato que contribuiu decisivamente para o povoamento e desenvolvimento da região foi a construção até a cidade de Uberaba, da ferrovia da Companhia Mogiana de Estrada de Ferro, que iniciou o tráfego de passageiros e mercadorias em abril de 1889, "diminuindo" as distâncias entre a região e a capital do país e, especialmente, fazendo acelerar o intercâmbio com a província de São Paulo que prosperava com a produção cafeeira.

A cidade acabou se tornando o caminho de praticamente todo o comércio dirigido ao Centro-Oeste, assim, Uberaba se destacava em relação a outras cidades do país e gerou em seus habitantes um sentimento de superioridade:

No núcleo urbano de Uberaba, uma série de novas construções e serviços passou a integrar a paisagem: arquitetura de estilo europeu, abertura de novas ruas, arborização de praças, hotéis, lojas de armarinhos, livraria, colégios $^{6}$, criação de um instituto politécnico, confeitaria e restaurantes com "menus à francesa", casas de jogos, associações artísticas e musicais, a realização de saraus e concertos (DANTAS, 2009, p. 71).

Contudo, apesar da incipiente pujança econômica, nas primeiras décadas do século $\mathrm{XX}$, a taxa de analfabetismo em Uberaba chegava a quase $70 \%$ da população, momento em que a escolarização das crianças era realizada quase exclusivamente de maneira informal nas casas dos primeiros professores do município. Na década de 1920 a educação básica foi assumida por iniciativas particulares, especialmente pela Igreja Católica detentora dos principais colégios para moças e rapazes que formavam a elite uberabense, em detrimento das crianças da classe trabalhadora. Essa forte influência da igreja na educação básica se estendeu

\footnotetext{
${ }^{4}$ A denominação "Desemboque" vem de certa parte do rio Grande, cujas águas embocando por um estreito canal entre serras, se subdividem em cinco braços apertados entre ilhas de terras (PONTES, 1998, p. 51). Foi na época, o mais importante núcleo populacional da região e pertenceu ao Goiás até 1816 quando foi transferido para Minas Gerais. A consequente necessidade de migração de parte de sua população para os sertões d'oeste foi aos poucos, fazendo com que a mineração cessasse por completo até os dias de hoje.

5 Milliet de Saint. Adolfe, falando das terras do Triângulo em seu Dicionário Geográfico e Histórico, escreveu: “... e eram conhecidas com o nome de Farinha Podre talvez por se ter ali achado um certa quantidade de farinha de mandioca corrupta que por esquecimento deixara algum sertanejo que ia em demanda de minas de ouro" (Dicionário Geográfico e Histórico do Brasil, v. I, p. 361).

${ }^{6}$ Foram criados dois colégios de confissão religiosa - marista e dominicano - que desempenharam importante papel na educação da elite local.
} 
para a educação superior com a fundação da primeira Faculdade de Filosofia, Ciências e Letras de São Tomás de Aquino - FISTA. ${ }^{7}$

O historiador André Azevedo da Fonseca (2010) apresenta dados importantes para compreender o contexto social, econômico e educacional de Uberaba no fim da década de 1940, fundamentais para justificar a importância da criação de cursos superiores para a cidade e região. A população somava quase 67 mil habitantes, com estimativa de 44 mil na área urbana. A infraestrutura da cidade era constituída por: dez clubes e associações de classe; oito casas de saúde; cinco hotéis; quatro jornais (dois diários e dois semanais); três grandes colégios, três escolas de comércio, três grupos escolares e 26 escolas municipais, em um total de 8,3 mil alunos; duas estradas de ferro; um aeroporto com oito linhas, que faziam rotas ao Rio de Janeiro, a São Paulo e a Belo Horizonte; malha rodoviária para cidades vizinhas; rede de telefones automáticos; cinemas; 14 agências bancárias e alguns estabelecimentos industriais. Os profissionais autônomos somavam: 52 médicos; 40 dentistas; 34 advogados; 23 farmacêuticos; 21 parteiras; 14 engenheiros; 62 enfermeiros e 114 contadores. Esses dados reforçam a expressão de Uberaba para a região e porque as iniciativas no sentido de se criar cursos de ensino superior nela.

Ainda que o campo da saúde se destacasse nas principais capitais, Uberaba foi considerada cidade-polo educacional e de tratamento de saúde. Uma parte significativa da população do Triângulo Mineiro, Alto Paranaíba, noroeste de São Paulo, Goiás e Mato Grosso enviavam seus filhos para cursar o ensino médio nos colégios da cidade e, depois, ingressar nas poucas faculdades existentes. Da mesma forma, os hospitais, raros no vasto "Sertão da Farinha Podre", recebiam um contingente expressivo de pessoas que demandavam serviços de saúde. Soma-se a isso o fato de Uberaba estar situada no centro da região do Triângulo Mineiro, geograficamente privilegiada, por encontrar-se entre a nova capital federal - Brasília (que estava em construção na segunda metade da década de 1950), a paulista e a mineira num raio de $500 \mathrm{~km}$ de distância aproximadamente.

A sociedade uberabense representada por uma elite intelectual, política e econômica, desejava que a região ampliasse a educação de nível superior, o que era facilitado pelas boas relações políticas com o governo federal e com os estaduais. Ao fim da década de 1950, as condições para isso eram favoráveis já que, além de Uberaba ser considerada uma das cidades mais desenvolvida de Minas Gerais, a ampliação desse nível educacional era uma política do governo federal para o interior. Segundo Luis Antônio Cunha (1983), essa política foi incentivada pelo Conselho Federal de Educação, facilitando o dificílimo processo de autorização para funcionamento dos cursos superiores e o credenciamento das faculdades particulares. Aumento da demanda pela urbanização, federalização de faculdades estaduais e particulares, agregação de escolas profissionalizantes, ascensão social das camadas médias e

\footnotetext{
${ }^{7} \mathrm{O}$ ensino superior em Uberaba, também teve início com a iniciativa dos católicos, pela atuação do bispo diocesano, Dom Alexandre Gonçalves do Amaral, e do Instituto Superior de Cultura que reunia a elite cultural uberabense constituída por professores, historiadores, religiosos e escritores ativos nessa organização. Com apoio de Alceu Amoroso Lima, principal articulador político da Igreja Católica junto ao Ministério da Educação, Dom Alexandre elaborou projeto de criação da Faculdade em conjunto com os irmãos maristas do Colégio Diocesano e as irmãs Dominicanas que já administravam o Colégio Nossa Senhora das Dores. Atendidas e cumpridas às exigências burocráticas e legais a Faculdade de Filosofia, Ciências e Letras de São Tomás de Aquino - FISTA iniciou suas atividades 1949, amparada legalmente pela autorização dada pelo Decreto $\mathrm{n}^{\circ}$ 26.044, de dezembro de 1948 (LOPES, 2016).
} 
equivalência dos cursos técnicos ao ensino secundário foram fatores que levaram à ampliação do acesso ao ensino superior no Brasil, sob o impacto do populismo. Segundo Cunha (1983, p. 43), “[...] se o Brasil tinha, em 1940, 12,6\% de sua população residindo em cidades de 50 mil habitantes ou mais, essa proporção já era de 22,9\% em 1960".

A organização do ensino superior regia-se pelo Estatuto das Universidades Brasileiras, de 1931, que delegava a competência de controle do ensino superior ao governo federal. Preconizava a universidade como padrão de organização do ensino superior. Mas concomitantemente continuaram existindo os estabelecimentos isolados de educação superior, que eram maioria. Em 1945, de acordo com Cunha (1983), existiam cinco universidades e 293 instituições isoladas, que atendiam mais de 27 mil estudantes. A Constituição Federal de 1946 preconizava que o ensino superior oficial devia ser gratuito para quem comprovasse insuficiência de recursos financeiros. Também alguns setores do Estado, já no início da República populista, defendiam a gratuidade do ensino superior. Assim, a participação da União e dos governos estaduais e municipais no custeio do ensino superior foi crescendo. De tal modo, em dezembro de 1950 a Lei n. 1.254 federalizou instituições de ensino superiores mantidas pelos estados, municípios e por particulares. Esse processo instaurador de mais oferta de vagas levou ao crescimento do ensino superior na década de 1950: o número de matriculados de 27.253 se elevou a 142.000 no fím da década.

Em 1950, havia 69.679 habitantes em Uberaba: 42.725 residiam no perímetro urbano e 26.954 no meio rural. Em dez anos, essa população cresceu 20,67\%; ou seja, em 1960 havia 87.835 habitantes: 72.053 urbanos e 15.780 do campo (IBGE, 1950-60). A migração do campo para a cidade foi de $41,45 \%$, motivada pelo desenvolvimento do comércio, fundação de escolas, presença de mais médicos, farmacêuticos, dentistas e advogados e por uma industrialização crescente, possibilitando mais empregos e condições de vida mais dignas e menos insalubres. Assim, as condições socioculturais eram bastante favoráveis a ampliação do ensino superior, mas a ação política da elite local foi determinante para a criação da FMTM.

\section{Faculdade de Medicina do Triângulo Mineiro: Atos Fundantes}

Ao fim do século XIX e nas décadas iniciais do século XX, as faculdades de Medicina foram temas de debates num movimento liderado por professores do curso de Medicina do Rio de Janeiro. Reivindicava-se mais autonomia administrativa e pedagógica nas escolas da área, ou seja, menos interferência no Estado; e buscava-se criar mais faculdades de Medicina. Esses pleitos eram transmitidos aos estudantes da escola do Rio de Janeiro, os quais incluíam alguns uberabenses. A revista de medicina Progresso Médico (1881, p. 81) trazia em suas páginas alguns de seus pleitos:

Outro grande problema é que ainda somos poucos e assim seguramente não há médicos disponíveis para quem precisa e nem para sermos respeitados. [...] obviamente não deve existir um curso médico em cada rua. Não se pode banalizar a nossa nobre atividade, mas outros locais de estudo se fazem necessários em grandes cidades do Brasil. Para isso conto a iniciativa dos jovens que saem daqui diplomados. 
Seria necessária uma quantidade maior de médicos para os hospitais, para tratar os doentes, assim como mais médicos para ocupar outros espaços. Por exemplo, os serviços sanitários, cargos nas esferas governamentais e a docência. Disseminadas por professores da Faculdade de Medicina do Rio do Janeiro, essas ideias podem ter se alastrado em meio àqueles que seriam os fundadores da FMTM - ex-alunos dessa faculdade - e estimulado o propósito de criar a instituição uberabense.

É preciso reconhecer que antes da criação da FMTM Uberaba concentrava diversas iniciativas no campo da medicina que a projetava enquanto polo avançado nessas discussões na região, considerando-se sua condição de cidade interiorana. Desde 1927, contava com a Sociedade Médica que, a partir de 1947, passou a realizar o Congresso Médico do Triângulo, promovendo discussões sobre os dados da saúde na região e no Brasil, como por exemplo, a presença de importantes professores e pesquisadores brasileiros nesses eventos discutindo-se o mal de Chagas. Não a toa que foi lançada no dia 7 de maio de 1950, a "Campanha Nacional contra o mal de Chagas" em Uberaba. Por essa característica, tornou-se notória na região do Triângulo Mineiro como centro importante não apenas de atendimento médico à população de várias cidades, mas também de estudos na área da saúde (LOPES; CHAPADEIRO, 2003).

Nesse contexto tiveram início os primeiros movimentos relacionados à intenção de fundação de uma Faculdade de Medicina na cidade. Essa seria a quinta escola de ensino superior do município (já funcionavam a Faculdade de Odontologia do Triângulo Mineiro, a Escola de Enfermagem Frei Eugênio, a Faculdade de Filosofia, Ciências e Letras de São Tomás de Aquino e a Faculdade de Direito).

Ainda de acordo com Lopes e Chapadeiro (2003) a Faculdade de Medicina do Triângulo Mineiro surgiu de uma disputa política partidária entre o Partido Social Democrata (PSD) e o Partido Trabalhista Brasileiro (PTB). A sociedade uberabense estava descontente com a política tributária do Estado de Minas Gerais, governado de 1950 a 1954 por Juscelino Kubitschek de Oliveira, e que seria o candidato do PSD a presidência da república na sucessão de Getúlio Vargas. Dessa forma, crescia na cidade o número de eleitores para o candidato paulista Ademar de Barros, do Partido Social Progressista (PSP).

Também o doutor Randolfo Borges Júnior (1983), professor e ex-diretor da FMTM relatou que a criação dessa instituição se originou sob a ótica política e a partir de atos de vandalismos promovidos pela cidade. Os uberabenses estavam imensamente insatisfeitos com a cobrança de taxa de impostos estaduais altas e impositivas, partiram para destruir prédios públicos especialmente as coletorias de arrecadação.

Diante desse fato, o então governador JK propôs por meio das Associações de Classes a realização de uma sondagem com o objetivo de conhecer os maiores anseios da população uberabense. Tratava-se de uma estratégia para contornar a situação política e retomar os votos que estava perdendo na região. Assim, em abril de 1953, reuniu-se na Associação Comercial e Industrial de Uberaba (ACIU) com as lideranças da cidade, que culminou com o pedido que a cidade tivesse um curso de medicina.

Com a aprovação da Assembleia Legislativa, Juscelino Kubitschek doou o prédio da Penitenciária do Estado para se implantar a Faculdade de Medicina do Triângulo Mineiro e vinte milhões de cruzeiros em títulos da dívida do Estado, cujos juros manteriam a instituição em sua fase inicial. A criação da FMTM pode ser melhor compreendida segundo o relato de alguns fundadores, a exemplo de Allyrio Furtado Nunes. Pesquisador e médico em Goiânia, recebeu o convite do irmão, Mozart Furtado Nunes, para se juntar ao grupo que articulava o 
curso médico, assim, participou da criação e implantação do mesmo, assumindo a cadeira de Bioquímica. Permaneceu na faculdade até sua aposentadoria.

Dr. Allyrio resumiu tudo em sua emoção dizendo: a Faculdade de Medicina foi um feito altruísta de um grupo de médicos corajosos e tenazes, estudiosos e trabalhadores, filiados ou entusiastas do PR, PSD, UDN e PTB. Um feito de educadores, que permaneceram com sua cria, até o final de suas vidas de trabalho. (UFTM, 1997, p. 5).

Em razão de falecimento do fundador José Soares Bilharinho, coube a Edison Reis Lopes, professor da FMTM e amigo, relatar que Bilharinho dizia que JK se adiantou no processo de expansão das escolas de medicina em Minas Gerais ao tomar conhecimento da meta de Vargas, então presidente da República, de criar mais cursos de Medicina.

Araújo (2000) destaca que uma das metas do governo Getúlio Vargas foi aumentar o número de faculdades de medicina pelo país, encerrando seu governo em 1945, com mais 13 escolas médicas criadas. A disseminação das escolas médicas na primeira metade do século XX integrou o projeto de modernização do país e, também, de reconhecimento do papel social e educacional do médico nesse cenário de grandes mudanças.

O então deputado federal Mário de Ascenção Palmério, um dos fundadores da instituição, destacou que a criação da FTMT foi consequência de projeto conjunto entre ele o então governador JK que fizeram o seguinte acordo: o Estado de Minas Gerais doaria a FMTM o edifício da antiga Penitenciária de Uberaba e apólices estaduais, no valor de vinte mil contos de réis, inalienáveis, mas cujos juros seriam pagos, mensalmente, à faculdade. A Sociedade Médica do Triângulo Mineiro ficaria responsável por constituir o corpo docente que seria responsável por implantar o curso, elaborando o projeto para autorização de funcionamento e envio ao Conselho Nacional de Educação (UFTM, 1997, p. 6).

O grupo de fundadores foi composto por 18 membros sendo: 12 médicos diplomados pela Faculdade Nacional de Medicina da Universidade do Brasil, um advogado que também se graduou no Rio de Janeiro, na Faculdade Nacional de Direito, um médico formado na Faculdade de Medicina e Farmácia Fluminense, dois médicos graduados Faculdade de Medicina de Minas Gerais e o último formado na Faculdade de Medicina de São Paulo. Curiosamente a maioria dos médicos se graduou no Rio de Janeiro. Se a distância menor entre Uberaba e Belo Horizonte puder ser tomada como motivação para se formar na escola de Medicina de lá — sustentar os filhos seria menos oneroso —, não se pode afirmar que foi o bastante para anular a tradição da escola do Rio do Janeiro, faculdade que se destacava nacionalmente pelos professores consagrados que lá atuavam. Soma-se a isso a diversidade de opções culturais e as formas de lazer disponíveis (cinemas, bares, teatros etc., sem contar as praias). Não foram localizadas informações referentes à instituição cursada por um dos médicos fundador. O deputado federal cursou Matemática na Faculdade de Filosofia da Universidade de São Paulo (USP). Desses 18 fundadores, 7 ocuparam cargos políticos de vereador, viceprefeito, prefeito, deputado estadual e federal. Tinham exercido cargos de influência sobre as decisões de interesse do município. 
Segundo Herschmann e Pereira (1994, p.44), no processo de modernização do país, o Estado teve papel importante nessa tarefa e contou com a ação de novos sujeitos, cujo prestígio social ascendente os lançava na aventura política, a partir de suas atividades profissionais, tais como médicos, advogados, engenheiros e educadores, "novos intelectuais", que pleiteavam desempenhar funções complementares junto aos governos municipais, estaduais e federal.

Basta lembrar-nos que muitas medidas sanitárias, que dizem respeito aos melhoramentos de higiene das cidades, seriam impossíveis sem o concurso do engenheiro, para bem se compreenderem os pontos de contato entre essas profissões. Os processos médicos de saneamento são sempre combinados com o de engenharia, onde o médico termina sua obra, o engenheiro começa a sua, e ambos têm um campo comum de trabalho no aperfeiçoamento das condições higiênicas (HERSCHMANN; PEREIRA, 1994, p.44).

O primeiro diretor da FMTM Mozart Furtado Nunes destacou que a mobilização do grupo de fundadores foi rápida. Logo foi convidado a assumir o cargo de diretor da FMTM. Ficaria com a responsabilidade de conduzir o processo de criação e funcionamento, conforme relatou o próprio Furtado:

Em sua casa, Palmério falou-me dos entendimentos que mantivera com o Dr. Juscelino, durante viagem feita a Diamantina, dos quais resultara a afirmação da sugestão dada aqui, e terminou dizendo: "concordei com Juscelino, mas estabeleci uma condição: que você, Mozart, seja o Diretor da Faculdade. Você tem 48 horas para me responder; se aceitar fundaremos a Faculdade; senão, está encerrado o assunto. Antes quero preveni-lo que você vai arrasar com sua vidinha boa. Eu sei o que são os médicos, cheios de melindres". Minha resposta foi rápida: "ainda me sinto moço bastante para enfrentar uma empreitada como esta; porém velho demais para pensar dois dias ao tomar uma resolução de tão grande interesse para Uberaba e para a nossa região. Eu topo a parada". Era dia 20 de abril. No dia 22 fomos a Uberlândia para que eu fosse apresentado ao Governador JK. De Uberlândia voltei Diretor da Faculdade de Medicina, a ser fundada. (UFTM, 1997, p. 8).

O diretor seguiu para o Rio de Janeiro em setembro de 1953, para receber orientações sobre o processo de formalização legal da criação da FMTM e do Curso de Medicina. Foi orientado a pesquisar e estudar os Regimentos das Faculdades de Medicina de Juiz de Fora, de Pernambuco, de Salvador, de Santa Maria e Católica de Belo Horizonte. Realizadas as anotações necessárias, deu início a procura e organização do material necessário para o equipamento mínimo exigido pela legislação educacional para que se pleiteasse a concessão da indispensável licença de funcionamento da FMTM.

De regresso a Uberaba conheceu Benedito do Espírito Santo, secretário acadêmico da faculdade de Direito, posteriormente aprovado em concurso público na FMTM, que tinha conhecimentos e experiência relacionados com a legislação e organização acadêmica do ensino superior, contribuindo para a instrução adequada do processo de criação da FMTM que 
com a devida documentação legal foi entregue na seção de protocolo do MEC pelo diretor Mozart Furtado Nunes, em 27 de outubro de 1953, para a autorização de funcionamento. O prazo entre a visita de Mozart Furtado ao MEC e o protocolo de abertura do processo foi menos de dois meses. A organização da documentação pelos envolvidos na criação da FMTM foi rápida, demonstrando que não podiam perder a oportunidade política aberta pelo governo.

A legislação educacional exigia a visita in loco de inspetores do MEC para avaliar se a organização dos espaços físicos e as condições pedagógicas mínimas para funcionamento do curso superior de Medicina estavam coerentes com a documentação constante no processo de autorização da criação da instituição. No fim de novembro de 1953, Mozart Furtado recebeu nas instalações improvisadas para funcionamento da FMTM, da Faculdade de Odontologia do Triângulo Mineiro, Cesar do Val Villares, inspetor do MEC. Informou o inspetor que havia encontrado tudo em ordem conforme documentado no relatório de avaliação. Um único incidente aconteceu: a Santa Casa não havia assinado o convênio com a FMTM para a realização do estágio curricular hospitalar (internato) dos alunos. Entretanto, como o Hospital da Criança também havia sido indicado para realizar as práticas hospitalares, o inspetor se deu por satisfeito com essas instalações e deu prosseguimento a tramitação do processo (LOPES, 2016).

O CNE aprovou, por unanimidade, a autorização para funcionamento da FMTM. O processo foi homologado pelo ministro da Educação. O Decreto $\mathrm{n}^{\mathbf{0}} 35.249$ autorizando a criação da FMTM foi assinado por Vargas no dia 24 de março de 1954 e publicado no Diário Oficial da União de 30 de março de 1954. Araújo relata que às 21 h de 28 de abril de 1954 foi instalada, pelo governador JK a Faculdade de Medicina. JK fora convidado a proferir a aula inaugural para a primeira turma de alunos aprovados no exame vestibular. Momento importante para a história da educação e da medicina do Triângulo Mineiro. O salão da Faculdade de Odontologia do Triângulo Mineiro estava abarrotado de representantes uberabenses da área da educação, da administração local, de comerciantes, dos 52 alunos aprovados em vestibular e do povo em geral, que lotou o edifício, ocupando salões, corredores e escadarias. "Entre vivas e aclamações o Governador foi introduzido no salão nobre." (ARAÚJO, 2000, p. 207).

A aula inaugural proferida por $\mathrm{JK}$ e dirigida aos 52 primeiros alunos teve início às $22 \mathrm{~h}$, tendo sido interrompida com frequência por aplausos e durou quase 50 minutos. Araújo (2000, p. 208) conta que, durante o discurso improvisado, o governador também médico:

Abordou as relações do seu programa de energia e transportes com a melhoria do ensino superior do interior, passando a fazer brilhante exposição do progresso da medicina, trecho em que se demorou, demonstrando impressionante cultura sobre o assunto. Defendeu a necessidade da difusão do ensino superior no interior do País e se congratulou com Uberaba, fazendo ainda, para os alunos da nova Faculdade, a definição dos deveres do médico e dos objetivos da medicina. Por fim, exaltou a capacidade realizadora do povo do Triângulo Mineiro, uma vez que já contava agora Uberaba com as Faculdades de Filosofia, de Odontologia e Farmácia, de Direito e de Medicina e, dentro de poucos meses, contará também com o Centro de Preparação de Oficiais da Reserva - CPOR. 
Como a FMTM nasceu sem espaço físico, funcionou durante os dois primeiros anos em salas e laboratórios da Faculdade de Odontologia do Triângulo Mineiro. Era necessário substituir "a algema pelo bisturi”, slogan usado sempre pelo professor Mauritano, que em 1958 assumiu a cadeira de Fisiologia da FMTM, para vencer os desafios iniciais do funcionamento de um curso de Medicina concomitantemente à fundação de uma instituição de ensino superior. Para esse fim, trabalharam obstinadamente alunos, professores, autoridades políticas, entidades de classe e sociedade local, a fim de que a instituição prosperasse. Ainda assim, como dizia monsenhor Juvenal Arduini, a FMTM era uma semente miúda quando se iniciou em 1954. Não era o nada, mas era o quase nada, porém, a faculdade se consolidou e se transformou em sólida instituição de ensino médico da região, estabelecendo intercâmbios no país e no exterior (LOPES, 2016).

O grande problema para início do curso de medicina era a contratação dos professores das diversas áreas médicas. Em meados da década de 1950 não havia em Uberaba médicos especializados para ocupar todas as cadeiras previstas no currículo do curso de Medicina. De fato dos professores que assinaram o termo de compromisso para autorização da FMTM, alguns deixaram de assumir suas cadeiras apresentando justificativas acatadas pelo diretor.

A cadeira - ou cátedra - era definida como unidade operativa de ensino entregue à responsabilidade de um professor denominado catedrático. De acordo com Veiga (2007), o Estatuto das Universidades Brasileiras definiu que o corpo docente de faculdades e universidades seria composto por professores catedráticos, os titulares das cadeiras. No Brasil, os privilégios do professor catedrático adquiriram feição histórica, apresentando-se tal regime como núcleo central das instituições universitárias. Além disso, a ideia de cátedra contida naquele estatuto ganhou força nas constituições federais de 1934 e 1946.

Embora a Constituição prescrevesse concurso de provas e títulos para contratar professores, o Ministério da Educação e Cultura (MEC) abriu precedente para que todos os indicados para a FMTM fossem considerados contratados ou interinos, até a realização de concursos públicos. O provimento para o cargo de professor catedrático sem concurso estava previsto na Carta Magna como exceção; ou seja, quando se tratasse de “[...] profissional insigne que tenha realizado invento ou descoberta de alta relevância, ou tenha publicado obra doutrinária de excepcional valor" e aprovado por dois terços da congregação (BRASIL, 1946, art. 56).

Decorrida a primeira nomeação (os dez anos iniciais), o professor catedrático podia se recandidatar ao cargo - neste caso, passaria por concurso de títulos. Se reconduzido, adquiria garantias de vitaliciedade e inamovibilidade (BRASIL, 1946, arts. 58 e 59). Assim o diretor da instituição se valeu desta brecha da legislação para compor o corpo docente. Cada cátedra disporia dos equipamentos mínimos necessários à efetivação e ao desenvolvimento do curso, a exemplo de laboratórios equipados, biblioteca, instrumentos etc.

O diretor realizou viagens pelas capitais mais próximas, especialmente Rio de Janeiro, Belo Horizonte e São Paulo. A indicação de médicos com suposta "capacidade técnica e intelectual" para o trabalho de ensinar foi favorecida, de forma geral, pelos mestres catedráticos das faculdades de Medicina daquelas cidades. A primeira viagem foi a Belo Horizonte, em busca de docente para a cadeira de Histologia. De acordo com a informação encontrada nos documentos, com a ajuda do professor Luigi Bagliolo, da Faculdade de Medicina de Minas Gerais, foi indicado o professor Edmundo Chapadeiro. Para assumir a cadeira de Anatomia, foi contratado Olavo Soares de Andrade. Além disso, o diretor 
convencera seu irmão, Allyrio Furtado Nunes, a se mudar de Goiânia para Uberaba e assumir a cadeira de Química. Esses professores permaneceram na faculdade até se aposentarem. Salles Jesuino aceitou o convite para integrar o grupo das cadeiras básicas e assumiu a cadeira de Fisiologia até 1958, quando esta se agrupou à cadeira de Anatomia.

Liberato J. A. Dio Dio, professor da Faculdade de Medicina de Belo Horizonte e médico influente na área, foi encarregado, pelo professor Renato Locchi, da Faculdade de Medicina de São Paulo, de contribuir para a FMTM. Destacou-se como colaborador na instalação da faculdade uberabense. Graças ao seu empenho vieram do Rio do Janeiro César Pinto, Francisco Mauro Guerra Terra e Pedro Falcão; porém somente Francisco Mauro assumiu a cadeira de Neurocirurgia; os demais não constam nas relações de docentes da FMTM. Por sua indicação, de São Paulo veio Homero Pinto Valada, para ser titular da cadeira de Clínica Psiquiátrica. Na mesma época, de Belo Horizonte, o diretor da FMTM trouxe Josefino Aleixo, para a cadeira de Clínica Dermatológica e Sifilográfica. Da cidade vizinha de Uberlândia, Eduardo Velloso Viana aceitou o convite para assumir a cadeira de Oftalmologia. Para titular da cadeira de Otorrinolaringologia, foi convidado Aziz Miguel Hueb, médico na cidade. Por fim, o diretor convenceu o então colega uberabense Edelweiss Teixeira, inspetor de ensino do MEC, a se juntar ao grupo pioneiro do ensino médico em Uberaba e assumir a cadeira de Higiene. "As aulas de Filosofia acrescidas ao currículo obrigatório, foram ministradas pelo Exmo. Sr. Prof. Cônego Juvenal Arduini, com a maior normalidade" (FMTM, 1955). Essa cadeira tratava dos aspectos de formação filosófica e humanista do currículo.

Dessa forma, os critérios de seleção e admissão dos professores foram informais e personalizados, baseados na recomendação de médicos e/ou professores influentes, ou seja, sem concurso público, sem entrevistas e sem análise de currículo. O convívio de Mozart Furtado com seus mestres do Rio de Janeiro lhe proporcionou uma visão ampliada da necessidade de garantir que alguns docentes se dedicassem ao curso em tempo integral. Em primeiro lugar, porque seria difícil contratar professores auxiliares, por falta de recursos financeiros; em segundo lugar, porque se dedicariam não só às aulas, mas também à realização de pesquisas, de relevância para projeção e notoriedade de uma faculdade de Medicina localizada no interior do país.

Como se pode deduzir dos contatos realizados durante as viagens do diretor, na década de 1950, havia poucos professores especializados com disponibilidade e vontade de se dedicarem à docência integralmente e mudarem seus domicílios, a maioria da capital para o interior. Ainda assim se sabe que Edmundo Chapadeiro, Olavo Soares de Andrade e Allyrio Furtado Nunes aceitaram o convite para a docência e assumiram suas cadeiras em dedicação integral; depois se somou a eles Mauritano Rodrigues Ferreira. Há registros de que a criação desse regime docente de dedicação integral, de fato, projetou a FMTM entre as faculdades de Medicina do país. Também abriu caminhos para que a fundação Rockefeller, dos Estados Unidos, na pessoa de seu diretor na América do Sul, Robert Briggs Watson, realizasse investimentos financeiros na construção e no aparelhamento de laboratórios das cadeiras básicas (LOPES, 2016). Na visão de Teixeira (2005), fatos como esses caracterizaram a existência das escolas superiores profissionais com ensino universitário de excelência. Não por acaso, quando, em 1920, aglutinaram-se essas escolas sob o regime de universidade, somente as de Medicina estavam em condições reais de participar desse projeto. 
No primeiro ano letivo do curso, tiveram início três cadeiras, com exigência de três professores. Hélio Angotti, um dos fundadores, assumiu a cadeira de Anatomia provisoriamente, até a chegada de Olavo Soares Andrade. Não havia professores auxiliares nem assistentes para contribuir com os catedráticos. A contratação dos docentes ocorreu de forma gradativa, de acordo com a definição do currículo e/ou as alterações por causa dos ajustes necessários a uma instituição educacional em fase de implantação, onde havia muito a ser feito.

A FMTM graduou 49 alunos oriundos de Uberaba ao final do período 1959 a 1965. Em Minas Gerais, foram 173 formados. Esses números foram acompanhados de perto pelo número de alunos que vieram de São Paulo: 105 graduados, sendo 38 oriundos da cidade de São Paulo. Também foi possível constatar que a FMTM recebeu alunos, em menor quantidade, de Goiás, Mato Grosso, Paraná, Rio de Janeiro, Espírito Santo e do Distrito Federal; assim como alunos de outros países naturalizados brasileiros puderam concluir o curso nessa instituição. Não foram identificadas as cidades de origem de 52 alunos (LOPES, 2016).

No ano de 1959, próximo da formatura da primeira turma do curso de Medicina, os aspectos internos e externos da arquitetura do Prédio da FMTM chocavam pela falta de realização de reformas, tornando-se um casarão velho e arruinado. Os alunos queriam "um melhor aspecto para aquela casa quando da ocasião de formar-se a primeira turma de médicos" (FMTM, 1964, p. s/n). Compreendendo que nada poderia ser feito com os recursos financeiros de que dispunha a instituição, iniciaram por intermédio do Centro Acadêmico Gaspar Vianna (CAGV), uma campanha junto à sociedade local para angariar fundos e transformar o antigo prédio da penitenciária numa Faculdade de Medicina. Esse desejo dos alunos foi despertado pelo recém-chegado professor Mauritano Rodrigues Ferreira, que apresentou um projeto de reforma sem custos para a instituição, chamado "operação MED”.

A "operação MED" chegou ao noticiário de jornais como o Independente de São Paulo, que no dia 28 de maio de 1959 estampou, na página 5, esta manchete: "UM PUNHADO DE BRAVOS. Em Uberaba, alunos e professores estão transformando uma penitenciária em Faculdade de Medicina. Grilhões são substituídos por bisturis" (FMTM, 1997, p. 48). O jornal informa que médicos, alunos e professores estão fazendo trabalho braçal, como simples operários da construção civil, trabalhando com entusiasmo a fim de concretizar a única faculdade de Medicina no interior do Brasil Central. Asseverava que, até Brasília ter sua faculdade de Medicina, era a FMTM a instituição responsável pela formação de médicos para a região.

Figura 1 - Obras de reforma do prédio da FMTM em [1960]

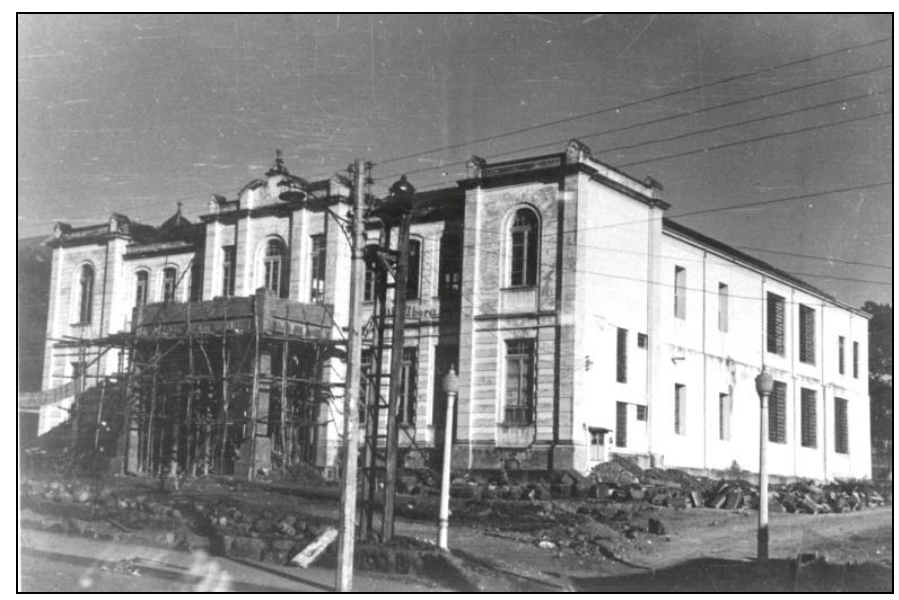

Fonte: Arquivo do Serviço de Fotografia da UFTM 
A reforma da FMTM ocorreu durante todo o ano de 1959 e tornou-se motivo de muito orgulho para os alunos. As mudanças mais importantes foram a substituição dos degraus de tijolos das escadas de acesso ao prédio por patamares de mármore, substituição das escadarias, corredores e corrimões de madeira desgastados e inseguros, por sólidas escadarias e redistribuição das dependências internas. Assim, o prédio pôde receber os convidados dos formandos de 1959.

Com a finalização das reformas, a demonstração de sacrifícios e capacidade de iniciativa e trabalho, a comunidade acadêmica da FMTM se revestiu de mais ânimo e credibilidade para buscar nas autoridades a federalização da instituição. Tornou-se evidente a falta de recursos financeiros para o funcionamento do oneroso curso de Medicina.

\section{Federalização: Alternativa para a Sobrevivência do Curso Médico}

O processo de federalização da FMTM esta registrado no relatório de gestão da FMTM de 1954 a 1960, onde Mozart Furtado destacou “(...) opiniões e lembranças: passagens marcantes de sua gestão" (FMTM, 1997, p. 17). As anuidades pagas pelos alunos e a dotação anual disponibilizada pelo governo federal não eram suficientes para o custeio que um curso de Medicina demandava. A saída para a situação passou a ser federalização: objetivo perseguido energicamente pelo diretor Mozart Furtado.

O ano de 1956 comemorava o centenário de Uberaba, apresentando-se como uma das grandes oportunidades para reivindicações de melhorias para a cidade. Assim, em maio desse ano, as festividades da exposição agropecuária da raça zebuína foram, pela primeira vez, inauguradas por um presidente da República, Juscelino Kubitschek. Logo depois de iniciar seu mandato, recebeu das mãos do diretor da FMTM o primeiro pedido de federalização da faculdade, reforçado pelo pedido do Centro Acadêmico (CAGV), que também entregou ao presidente um memorial assinado por todos os alunos da faculdade.

Entretanto, o presidente ponderou que ainda era cedo para que se conseguisse a aprovação das instâncias federais para a criação de uma instituição federal de ensino superior. Como uma instituição de ensino é constituída por grupos sob muitos aspectos heterogêneos, devido especialmente a políticas partidárias, houve articulações para entravar o crescimento da instituição. Quando souberam da ação do diretor, os membros e presidente da sociedade mantenedora da FMTM ficaram ressabiados, pois não haviam sido consultados sobre sua pertinência. O diretor assumiu que havia levado ao presidente da República a demanda sem fazer as devidas consultas internas. Para remediar a situação, convocou plenária para discussão do assunto, e não encontrou opositores.

Fortalecido pela decisão colegiada da assembleia realizada, Mozart Furtado procurou o presidente novamente, por ocasião de nova visita a Uberaba. Em sua companhia, estava o acadêmico Leopoldo de Castro e Silva, presidente do CAGV. Juntos, rememoraram a Juscelino Kubitschek a solicitação anterior. Expuseram as dificuldades para continuidade do curso, como precariedade e inexistência de alguns laboratórios e equipamentos especializados, além da falta de recursos financeiros suficientes para remuneração dos funcionários técnicos e docentes. Esse momento constituiu um efetivo apelo ao presidente que, no governo de Minas Gerais, articulou a criação da faculdade. Sensibilizado, requisitou agendamento de reunião no Palácio do Catete para tratar do assunto. 
Em 19 de setembro de 1956, para participar da reunião com o presidente, viajaram para o Rio de Janeiro Mozart Furtado, diretor da FMTM, Lauro Savastano Fontoura, presidente da mantenedora da FMTM, o prefeito de Uberaba, Artur Teixeira, e 19 alunos do curso de Medicina. Foram recebidos pelo então ministro da Educação Clóvis Salgado, pelo ministro de Gabinete da Presidência, Celso Brant, pelo ministro Paschoal Carlos Magno, diretor do ensino superior do MEC, e pelo deputado federal de Uberaba Mário Palmério. Lá cumpriram agenda de contatos e audiências de articulação com autoridades envolvidas.

O Presidente, serenamente e com o melhor humor possível, declarou que não era Presidente apenas de Minas e Uberaba, mas que ficássemos descansados que, antes de findar seu mandato, nos concederia a almejada federalização. E que, na ocasião oportuna, pediria a um deputado (e que este seria o deputado Mário Palmério) para encaminhar a sua mensagem. (FMTM, 1997, p. 18).

Como ação concreta imediata da reunião, o ministro da Educação garantiu dotação orçamentária de 5 milhões de cruzeiros durante cinco anos para a FMTM. Somado a isso, o regime de dedicação integral de parte do corpo docente tornou-se fundamental para abrir caminhos à obtenção de mais recursos financeiros do MEC. Assim, em 1959, através de emenda parlamentar no Senado, conseguiu-se mais verba do Ministério da Saúde para o Hospital da Associação de Combate ao Câncer do Brasil Central, uma das unidades que funcionava como hospital-escola do curso de Medicina em Uberaba.

Entre 1956 e 1960, diretor, professores e alunos trabalharam com afinco para o processo de federalização da FMTM cientes de que seria a única forma para sua sobrevivência financeira. Em março de 1956, através do O Epíplon, veículo oficial de notícias do centro acadêmico, na figura do seu presidente Wander Magalhães Moreira, era lançada a campanha de federalização como objetivo máximo do CAGV. A campanha estendeu-se, através de avanços e recuos, obstáculos e apoios, até 1960. A divulgação da arrojada "operação MED" fortaleceu o CAGV, culminando com a visita dos candidatos ao governo de Minas Gerais - Tancredo Neves — e à presidência do Brasil — Henrique Teixeira Lott - que se comprometeram com os alunos e a direção quanto a envidar esforços em prol da federalização da instituição.

Nesse meio-tempo, um acontecimento marcou um momento que seria crucial para a federalização da instituição. Em 3 de maio de 1960, o presidente da República Juscelino Kubitschek chegou para inaugurar a exposição agropecuária de gado Zebu de Uberaba. Encontravam-se no aeroporto de Uberaba para recepcioná-lo as autoridades políticas locais, pecuaristas chefiados pelo presidente da Associação Brasileira de Criadores de Gado Zebu, além de populares desejosos de saudá-lo.

Porém, burlando a segurança presidencial, adentrou ao saguão do aeroporto um grupo de estudantes da faculdade de Medicina e, antes que o presidente desembarcasse, já estavam à sua espera nas escadas do avião. Os estudantes "arrebataram" o presidente e o levaram a um ônibus que os aguardavam nas proximidades do aeroporto, contrariando líderes políticos e pecuaristas que o recepcionavam. Juscelino Kubitschek se deixou levar até a sede do centro acadêmico da FMTM. 
O Presidente nela foi introduzido, carregado pelos alunos até a sede do Centro Acadêmico Gaspar Vianna. Após ligeira troca de discursos, JK escreveu sobre uma fotografia sua, a qual foi oferecida ao Centro Acadêmico, a seguinte frase: tudo farei que estiver ao meu alcance para federalizar esta escola, pois ela é a menina dos meus olhos. (BORGES JÚNIOR, 1983, p. 7).

O pedido de federalização da FMTM foi enviado por JK ao Senado em meados de 1960, após nova visita a cidade, quando mais uma vez as dificuldades do processo foram reforçadas por líderes locais. A população se organizou em "[...] passeatas, comícios e envio de centenas de telegramas à Câmara e à Comissão de Educação e Finanças" (LOPES; CHAPADEIRO, 2003, s/n). O presidente retornou à Brasília, onde enviou à Câmara dos Deputados projeto no qual propunha a federalização da FMTM e da Faculdade de Medicina de Diamantina, em Minas Gerais, sua cidade natal.

Em setembro de 1960, em nova visita de campanha política feita a Uberaba, o candidato à presidência Tancredo Neves e seu vice, o ex-ministro Clóvis Salgado, asseguraram que a federalização já era ponto pacífico no Congresso Nacional; porém, advertiram para a necessidade de que esse projeto fosse votado antes da realização das eleições. Enquanto a federalização tramitava nas instâncias de análise e aprovação, JK assinou o decreto 47.844, de 24 de dezembro de 1959, pelo qual a FMTM era reconhecida; ou seja, obteve o reconhecimento legal necessário à expedição dos diplomas acadêmicos.

Contudo, apesar do reconhecimento legal, o problema não estava resolvido. Por vários problemas passava a faculdade. Rendas escassas comprometiam até o pagamento dos professores e funcionários, constituindo-se até mesmo em ameaça de fechamento. Para que a FMTM continuasse a oferecer o curso de Medicina, era imperativo transformá-la em Instituição Federal de Ensino Superior. Em 27 de agosto de 1960, o prefeito Jorge Furtado esteve em Brasília, com o presidente Juscelino Kubitschek, portando ofício de reforço à necessidade de abreviar a aprovação do projeto de federalização da FMTM antes do término de seu mandato presidencial. A resposta do presidente foi de tranquilidade. Ele considerava que esse fato já estava consolidado no Congresso Nacional, que trabalhava para aprovar o processo de federalização das duas faculdades de Medicina interioranas de Minas Gerais.

Os trabalhos em prol da federalização da faculdade de Medicina não cessaram, mesmo com a tranquilidade transmitida pelo Poder Executivo Federal. Mozart Furtado foi ao Rio de Janeiro em 12 de outubro de 1960, para audiência com o ministro da Educação. Enquanto isso ficou acordado com Lauro Savastano Fontoura, presidente da sociedade mantenedora, que ele iria à Brasília acompanhar a tramitação do projeto de federalização, parado na comissão de educação. Já tinham sido realizadas sessões na Câmara dos Deputados com esse item na pauta; mas não houve quórum para votação.

Mozart Furtado se desencontrou com o ministro e, preocupado que estava com os encaminhamentos do processo de federalização, resolveu antecipar a viagem de retorno em um dia. Ele havia combinado com Savastano, presidente da sociedade mantenedora, de encontrá-lo em Belo Horizonte no dia seguinte, mas ligou para o presidente do CAGV, Wandir Ferreira de Souza, pedindo para encontrá-lo em Brasília naquele mesmo dia. Chegando a Belo Horizonte, o diretor da FMTM encontrou com Savastano, que, para sua 
surpresa, comunicou-lhe que havia mudado sua posição: agora era contrário à federalização. Tinha novo entendimento: a seu ver a FMTM, deveria ser transformada numa fundação. A partir daí houve muitos desencontros que trouxeram à tona pendências administrativas da FMTM e dividiram a opinião da comunidade acadêmica. Mozart Furtado tentou, em vão, conciliar os contrários à federalização com os favoráveis. Como resultado das divergências políticas, em 17 de novembro de 1960, ele renunciou ao cargo de diretor da faculdade para não prejudicar o processo de federalização.

Todavia, a nova diretoria CAGV, que tomou posse em outubro de 1960, na figura do seu presidente, Nelson Assis, e vice, Mário Lúcio Alves Batista, organizou os discentes, conclamando o envolvimento e a participação de toda a sociedade no que foi chamado de "campanha da federalização da FMTM". Buscaram firmar alianças com forças sindicais. O movimento foi para as ruas, com a realização de passeatas e comícios. Houve o envio de centenas de telegramas à Comissão de Educação da Câmara dos Deputados Federais. Na segunda quinzena de novembro, o CAGV organizou uma concentração popular na praça Rui Barbosa, no Centro. Desse movimento, foram enviadas ao gabinete presidencial mais de quatro mil solicitações de federalização da FMTM, dentre circulares, telegramas, cartas e ofícios.

Uma comissão de alunos constituída pelo CAGV acompanhou, na Câmara dos Deputados, a votação da federalização da FMTM, aprovada em 25 de novembro de 1960. Enviado ao Senado, o senador Reginaldo Fernandes ficou incumbido de relatar o processo, justificando a necessidade de aprovação para a sobrevivência dessa escola interiorana. Em 14 de dezembro de 1960, o processo de federalização foi aprovado pelo Senado. O jornal uberabense Lavoura e Comércio de 16 de dezembro de 1960 (p. 1) publicou a manchete: "Faculdade de Medicina: JK sancionará a federalização na próxima segunda-feira". Assim, a sanção presidencial da federalização da FMTM era aguardada com expectativa. Esse evento importante foi agendado para o dia 18 de dezembro de 1960. Estiveram presentes, no Palácio da Alvorada, representantes da direção e da congregação da FMTM e uma comissão do CAGV constituída pelos acadêmicos Nelson Assis, Álvaro J. Azuz, Hadel Rachid Daher, Oswaldino Pereira e Valdete Cabral (ASSIS, 1964).

Segundo os alunos, esse momento encerrou um capítulo de luta e glória na história da FMTM, conforme documentado pela "Mensagem da federalização do CAGV":

Nobre colega:

Um dos mais elevados ideais de nossa vida acadêmica tem sido concretizado na Federalização de nossa Faculdade. Novas e largas perspectivas abrem-se agora para a Faculdade de Medicina do Triângulo Mineiro (Federal). Assim ao enviar ao colega a íntegra da mensagem presidencial, lei aprovada, a nossa "Mensagem da Federalização" comentamos com o nobre colega alguns aspectos do fato consumado, para felicidade nossa, em 18 e dezembro deste, para nós, memorável ano de 1960. [...] Nossa luta, entretanto, não para aqui. Entendemos que o Concurso para provimento de Cátedras é inadiável e, para isso, temos voltados os nossos objetivos. Principalmente naquelas mais deficientes. Temos de nos propor a sermos, agora, vigilantes, altivos e responsáveis desta Escola Pública, Escola Federal. Agora, mais que nunca, nós constituímos a Escola. Não mais alguns, grupos ou o Prédio. Sua expressão situa-se em muito mais amplas dimensões que só o elemento 
humano que se forma pode atender. Nós, alunos, a única força atuante contínua do processo da Federalização e, que tivemos no Presidente Juscelino Kubitscheck de Oliveira nosso grande patrono, não podemos parar. [...] Nelson Assis — Presidente do CAGV. (ASSIS, 1964, s. p.).

A partir de 1950, ocorreram numerosas federalizações de Instituições de Ensino Superior. As escolas isoladas, em especial as localizadas nas capitais, foram aglutinadas em universidades. Esse mesmo processo ocorreu com as faculdades católicas. Segundo Cunha (1983, p. 94), "Raras são as universidades hoje existentes que escaparam a esse processo aglutinador". Como exceção, pode-se citar a Universidade de Brasília e Universidade Federal de São Carlos, criadas após 1960. Mas, de acordo com o autor, a aglutinação das faculdades isoladas em universidades foi condutora da transformação do ensino superior na República populista, de modo que em 1964 o Brasil tinha 39 universidades.

\section{Considerações Finais}

Nesse espaço conclusivo, constata-se que para o bom desfecho da criação da FMTM, confluíram, inicialmente, as boas relações que os médicos uberabenses mantiveram com líderes políticos em todos os níveis dos poderes públicos, a ação dos estudantes promovendo ações em prol da manutenção da instituição e de sua federalização, além do apoio da sociedade triangulina. Destacam-se numerosos momentos dos governos de Getúlio Vargas e Juscelino Kubitschek — este como governador de Minas Gerais e presidente da República quando a criação dessa instituição foi assunto pautado nas discussões da capital. A proposta feita por Kubitschek — “[...] fundar em Uberaba uma faculdade de medicina, a exemplo de Juiz de Fora" (FMTM, 1997, p. 8) - foi o motor impulsor desse movimento, ainda que se possa afirmar que a sociedade uberabense desejasse criar um curso de Medicina para formar seus "filhos" sem o ônus do deslocamento para outras cidades.

Nesse processo, foi proeminente o trabalho de Mozart Furtado Nunes que, aos 50 anos de idade e vivendo "[...] serena e despreocupadamente entregue aos trabalhos de rendosa e seleta clínica" (FMTM, 1997, p. 8), não hesitou em assumir a liderança do processo político, burocrático e desgastante de criar e instalar um curso de Medicina em uma instituição de ensino superior. Também não se pode negar a importância dos fundadores da segunda metade do século XX que, não se conformando com o papel de atuação secundária na sociedade uberabense, tomaram para si o compromisso que era do poder público: dar novos rumos à medicina e à saúde uberabense.

A constituição da FMTM congregou médicos da cidade e especialistas de outras regiões, criando um palco de formação de profissionais médicos e do ensino médico como profissão. Ali, naquele espaço pensado para a educação médica, arregimentou-se um corpo de médicos-professores-especialistas que se envolveu com afinco na instalação da recém-criada FMTM, mesmo que alguns residissem em cidades distantes. Garantiram o status da escola e um ensino de qualidade dentro da visão do período aos alunos que por lá passaram, dentre os quais alguns até se tornaram professores da faculdade. 
A federalização da FMTM foi consequência de lutas travadas pelos líderes estudantis primeiro por meio da "operação MED" e depois pela campanha de federalização, ações que garantiram a existência da instituição, enfrentando a escassez de recursos orçamentários para cobrir custos de manutenção de laboratórios, equipamentos, hospital, remuneração de professores e funcionários, dentre outros. Coube a Juscelino Kubitschek, como presidente, já nos derradeiros dias de mandato, o papel central de apoiar o grupo nessa empreitada.

\section{Referências}

ARAÚJO, Fernando. Juscelino Kubitschek, o médico. Lithera Maciel, Belo Horizonte, 2000.

ASSIS, Nelson. A realidade dos dez anos: a história da fundação da FMTM e do Centro Acadêmico Gaspar Viana. Suas vidas em 10 anos. Revista Centro Acadêmico Gaspar Vianna, Uberaba: FMTM, número especial de 10ª aniversário da FMTM, 1964.

BILHARINHO, José Soares. História da medicina em Uberaba. Uberaba: Academia de Letras do Triângulo Mineiro, 1980, vls. 1 ao 3.

BORGES JÚNIOR, Randolfo. Nossa faculdade de medicina, sua história, seu destino. Discurso proferido por ocasião da abertura do I Congresso Médico dos Ex-alunos da FMTM e III Congresso Médico da SMCU e VII Congresso Médico do interior da AMMG, em 1983. Uberaba, 1983, p. 1-2.

BRASIL. Constituição dos Estados Unidos do Brasil, 18 de setembro de 1946.

CHARLES, Cristophe; VERGER, Jacques. História das universidades. São Paulo: ed. UNESP, 1996.

CUNHA, Luiz Antônio. A universidade crítica: o ensino superior na República Populista. Rio de Janeiro: Francisco Alves, 1983.

CUNHA, Luiz Antônio. Educação e desenvolvimento social no Brasil. Rio de Janeiro: Francisco Alves, 1985.

FACULDADE DE MEDICINA DO TRIÂNGULO MINEIRO/FMTM. História e Médicos da Faculdade de Medicina do Triângulo Mineiro. Uberaba: Zardo, 1997.

FONSECA, André Azevedo da. A consagração do mito Mário Palmério no cenário político do Triângulo Mineiro (1940-1950). 2010. Tese (doutorado em História) Faculdade de História, da Universidade Estadual Paulista "Júlio de Mesquita Filho".

HERSCHMANN, Micael M.; PEREIRA, Carlos Alberto Messeder. A invenção do Brasil moderno: médicos, engenheiros e educadores no Rio de Janeiro (1870-1937). Rio de Janeiro: Diadorim, 1994. 
LOPES, Maria Antonieta B.; CHAPADEIRO, Edmundo. Projeto memória da FMTM. Texto impresso. Uberaba: Faculdade de Medicina do Triângulo Mineiro, 2003.

LOURENÇO, Luís Augusto Bustamante. O Triângulo Mineiro, do império à República: o extremo oeste de Minas Gerais na transição para a ordem capitalista (segunda metade do século XIX). Uberlândia: ed. UFU, 2010.

MACHADO, Maria Helena (Coord.). Os médicos no Brasil: um retrato da realidade. Rio de Janeiro: ed. Fiocruz, 1996.

OLIVEIRA, Armando Campos. Juscelino Kubitschek de Oliveira - um presidente diferente. Jornal da Manhã, Uberaba, MG, 2 de junho de $/ 2015$.

PONTES, Hildebrando. História de Uberaba e a civilização do Brasil Central. 2. ed. Uberaba: ed. da Academia de Letras do Triângulo Mineiro, 1978.

REZENDE, Eliane Mendonça Márquez de. Uberaba: uma trajetória socioeconômica 1811-1910. Uberaba: APU, 1991.

SANTOS FILHO, Lycurgo de Castro. História geral da medicina brasileira. São Paulo: ed. USP; Hucitec, 1977, vols. 1-2.

TEIXEIRA, Anísio Spínola. Ensino Superior no Brasil: análise e interpretação de sua evolução até 1969. Rio de Janeiro: ed. UFRJ, 2005.

UNIVERSIDADE FEDERAL DE MEDICINA DO TRIÂNGULO MINEIRO/UFTM. A importância e o papel decisivo do desembargador Lauro Fontoura na criação e federalização da FMTM hoje UFTM (Universidade Federal do Triângulo Mineiro. 1 dvd. Widescreen, colorido, 2010.

UNIVERSIDADE FEDERAL DE MEDICINA DO TRIÂNGULO MINEIRO. Hospital de Clínicas. Apresentação do Hospital de Clínicas. Disponível em: <http://www.uftm.edu.br/ hospitaldeclinicas/apresentacao>. Acesso em: 31 jun. $2015 \mathrm{a}$.

UNIVERSIDADE FEDERAL DE MEDICINA DO TRIÂNGULO MINEIRO/UFTM. Reitoria. FMTM: uma história de idealismo e coragem. Ana Luiza Brasil (Org.). Digitado, impresso, grampeado com marcas manuscritas de revisão e cortes em algumas páginas. Uberaba-MG, 1997, 66 p. [não publicado].

VEIGA, Cynthia Greive. História da educação. São Paulo: Ática, 2007. 